Please note! This text is the 'author accepted manuscript', a pre-final version, where changes made as a result of peer review process are reflected, but not changes made after that, in proof-reading etc. The published paper is under copyright, and the publisher should be contacted for permission to re-use or reprint the material in any form.

Reference to the published article: Tiselius, Elisabet \& Birgitta Englund Dimitrova. 2016. "Asymmetrical language proficiency in dialogue interpreters: Methodological issues" Translation, Cognition, Behaviour 2(2). 305-322. DOI 10.1075/tcb.00031.tis 


\section{Asymmetrical Language Proficiency in Dialogue Interpreters \\ -Methodological issues}

*Elisabet Tiselius, ORCID: 0000-0002-2285-6729

Stockholm University, Western Norway University of Applied Sciences

elisabet.tiselius@su.se

Institute for Interpreting and Translation Studies

Stockholm University

10691 Stockholm, Sweden

Birgitta Englund Dimitrova, ORCID: 0000-0002-0612-6814

Stockholm University 


\title{
Asymmetrical Language Proficiency in Dialogue Interpreters -Methodological issues
}

\begin{abstract}
Language proficiency of dialogue interpreters, who typically work in the public service sector, is an under-researched area. Unlike as is the case with conference interpreters, there is no generally accepted definition of proficiency levels of working languages for dialogue interpreters. This article discusses language proficiency in dialogue interpreting. It presents a methodological problem, namely, how to define and determine a given interpreter's stronger and weaker working language. We discuss different methods for determining the individual interpreter's stronger and weaker working languages, such as self-assessment, demographic, socio-linguistic questionnaire and test score (Dialang). We conclude that there is a need for more research in this area.
\end{abstract}

Keywords: Dialogue interpreting, language proficiency, language proficiency testing, Dialang, asymmetrical language proficiency.

\section{Introduction}

The most widespread type of dialogue interpreting is probably community interpreting. This type of interpreting is also called public service interpreting (PSI), as it is the type of interpreting used in many countries, and in different parts of the public sector, including medical encounters or migration interviews. It enables the majority language speaking representatives of a society to communicate with allophone language speakers such as refugees and immigrants or, indeed, indigenous minority language speakers. The participants in our study fall under this category, but we will use the term dialogue interpreter throughout this text.

The starting point for this study is a project funded by the Swedish Research council (VR 201601118) entitled Invisible process - cognition and working memory of dialogue interpreting. Its aim is to investigate the nature of cognitive resources in dialogue interpreting, with an array of research methods, including (1) Psychological tests measuring central executive functions of the working memory (ability to resist interference, ability to share attention between two tasks (dual tasking), ability to switch attention from one task to another (shifting)); (2) Language tests screening the language proficiency level of the interpreters' L1 and L2; (3) Video-recordings of (a) simulated semiscripted interpreted encounters, including challenges of interpreters' skills (aggressive turn-taking, long turns, challenging terminology), (b) eye-tracking of the interpreters' gaze during the encounter, and (c) retrospective interviews. In this article, we focus on the language tests.

One of the research questions in the project is whether dialogue interpreters apply different strategies for coping with cognitive load when interpreting into their L1 compared to when interpreting into their L2. Hypothesizing that the dialogue interpreter in public service interpreting often has asymmetrical language proficiency of the two working languages (see further below), we are interested in whether the asymmetry in language proficiency affects interpreting strategies and the interpreting product. In the project we have so far conducted two smaller studies, one investigating differences in (textual) strategies when working into a stronger vs. when working into a weaker language (Thomsen 2018), and the other investigating gaze-direction under the same conditions (Tiselius \& Sneed submitted). In both studies, there are indications of differences (of strategy use and gaze-pattern) depending on whether the interpreting is carried out into the participants' weaker or stronger language. 
We therefore assume that the difference between weaker and stronger language in the interpreting process certainly merits further studies. This question is also closely related to the issue of directionality in interpreting (Chang, C. \& Schallert 2007; Godijns \& Hinderdael 2005; cf. also below), by which we understand interpreting from L2 to L1 or vice versa, between languages of potentially different degrees of proficiency, i.e. asymmetrical proficiency. This brings us to the purpose of this paper which can be broadly stated as follows: how can the proficiency in the working languages of a given dialogue interpreter be defined and determined (by what method and measure?) for further study?

\section{Background}

\subsection{Language proficiency in interpreting}

In the literature on interpreting, the assumption about the interpreter's bilingualism is that the interpreter is a language expert or has very advanced proficiency in their working languages (MoserMercer 1994), but this assumption is mainly formulated within a conference interpreting context. Here, the awareness of the importance of differences in language proficiency is reflected in the established language scheme where an A-language is defined as an L1 or mother-tongue equivalent language. A B-language is defined as a near-native language over which the interpreter has full command both as a source and target language. A C-language, on the other hand, is a language of which the interpreter has a full understanding, but does not work into as the active command is not at near-native or native level (AIIC 2012). Hence, in conference interpreting, language proficiency is often formulated as a dichotomy where a language is either mastered at levels advanced enough for interpreting (A, B or C following AIIC standards) or not, and, in contrast to C-language, A and B languages are seen as functionally equivalent in the interpreting situation.

Conference interpreters tend to be rather homogenous linguistically. Although they come from diverse educational backgrounds, conference interpreters are either tested for their linguistic proficiency (and other background factors) as part of their admission test to a training programme, or they take the conference interpreting training as part (often at MA level) of a university program which also includes education in the relevant languages. This (relative) linguistic homogeneity is reflected in the established system (A, B, C language) for classifying the individual interpreter's working languages, i.e. language proficiency in his/her working languages. The impact of language proficiency has been investigated in simultaneous, sight translation or consecutive interpreting, where the interpreter would typically work into one language only (Tzou et al. 2011; Christoffels et al. 2006; de Bot 2000; Blasco Mayór 2015; Cai et al. 2015; Rosiers et al. 2015).

As we far as we have been able to determine, there is no systematic overview available of dialogue interpreters' educational and language backgrounds. This is certainly true for Sweden, but it seems to be true for most other countries as well. In our experience ${ }^{1}$, dialogue interpreters are a very heterogeneous group in their linguistic and educational backgrounds, which is probably to a large extent dependent on their language combination. Those who work in dialogue settings in the public service sector are often second language speakers of the majority language, i.e. the language of the institutions they interpret for. They can be early bilinguals, having grown up with two languages (in the family, and/or at school), or, they can be late bilinguals, having acquired their second language through formal education (at school, university), or through various language courses, self-study, or using the language and interacting with its speakers ${ }^{2}$. This is not to say, however, that all dialogue interpreters are second language speakers of the majority language. They can be heritage speakers of the other language, or as is the case with several of the participants in our study, native speakers of the majority language, having learnt the other language as a second language. We assume, however,

\footnotetext{
${ }^{1}$ Together the two authors cover over 40 years of both practical and theoretical work in the area of public service interpreting in Sweden.

${ }^{2}$ As is well known many languages in community interpreting are languages for which no formal education is available in the host country.
} 
that whatever their language background, their language proficiency in many interpreting situations is functionally asymmetrical (de Bot 2000).

\subsection{Bilingual proficiency and interpreting}

In research on bilingualism, contrary to interpreting research, the approach to bilingual language proficiency has developed into a continuum rather than a dichotomy (Romaine 1995). The individual who uses more than one language, albeit with difficulties, is at one end of the continuum and the balanced bilingual with equal mastery of two languages at the other. However, as Hulstijn (2015) points out, there are great differences in language proficiency not only for bilingual speakers, but also for monolingual speakers. Hulstijn also concludes from comparison groups in different studies on L2 proficiency that monolingual college students often serve as the reference point for studying L2 proficiency (Hulstijn 2015, 18): "The covert underlying assumption then is that language proficiency of such college students forms the norm for L2 learners." Obviously, this does not do justice to L2 learners' proficiency. Hulstijn instead proposes that language proficiency be seen as a dichotomy, although a slightly different dichotomy than the one used in conference interpreting research. In his BLC Theory, Hulstijn divides language proficiency into Basic and Higher (or extended) language cognition (BLC vs. HLC). Hulstijn then postulates that BLC is the language cognition that all native speakers have in common $(2015,21)$. The HLC, on the other hand, depends on the individual's cognitive abilities as well as exposure to language. In the framework of BLC theory, Hulstijn defines the native speaker in social terms as someone who acquired the language at a young age and maintains it into adulthood, and in linguistic terms as someone who has acquired BLC and some or several aspects of HLC. Using BLC theory, it can be argued that the dialogue interpreter needs to be bilingual at basic language cognition level and master several of the higher language cognition aspects, in both L1 and L2, in order to interpret to and from two different languages. For investigating language dominance, Hulstijn proposes tests of oral reception and production over reading and writing. Furthermore, in a discussion on the Common European Framework of Reference for Languages (CEFR), Hulstijn argues that many L1 speakers will never reach the highest levels of that framework ( $\mathrm{C} 1$ or $\mathrm{C} 2$ ) as they require advanced intellectual proficiency.

\subsection{Testing interpreters' language proficiency}

In research on interpreting, different studies determine participants' actual language proficiency in different ways; e.g., it can be tested with instruments developed for other purposes (e.g. TOEFL as in Tzou et. al. 2011 or Blasco Mayór 2015), by self-screening (as in Dillinger 1994 or Christoffels et. al. 2006) or by looking at participants' previous study records (Jiménez Ivars et al. 2014). Earlier research in interpreting studies and on conference interpreting has often found self-screening to be as effective as other types of tests (Dillinger 1994; de Bot 1992). However, one difficulty with selfscreening tests in the interpreting context is to accurately formulate criteria for language proficiency relevant for the task. Moser-Mercer (1994), in a recount of admissions tests in interpreting courses states that language proficiency is often tested either through a written translation test or through an interview and that most interpreter trainers intuitively know what language levels are required for interpreting. The way of determining language proficiency differs in studies on directionality also. Many studies do not test the actual level of language proficiency, but determine participant A or B's language either from their own statement (Chmiel 2016; Chang, C-Y. 2009; Bartłomiejczyk 2006) or via a study-specific questionnaire (Dose 2014; Nicodemus \& Emmorey 2013; Chang C. \& Schallert 2007). Dialang (cf. below) has been used in a study on directionality, but the study was focusing on about translators (Pavlović \& Jensen 2009).

For dialogue interpreting, various procedures are in place for testing in certification and/or educational contexts (Angelelli \& Degueldre 2002). To our knowledge, there are no generally accepted systems in place, in any country, to test systematically and classify the level of language proficiency of dialogue interpreters' different working languages. There are language tests for budding dialogue interpreters, e. g. in Norway (Tospråkstesten 2016). But the result of the test is not formulated as a certain level that has been attained (in a grid of several levels), but rather 'pass' or 
'fail' for the necessary language proficiency to be admitted to an interpreting course. Angelelli (2007) developed a language proficiency test for interpreting specifically aimed at medical interpreting and thus not examining a general language proficiency level. In Sweden, a test is used (in the so called folk high schools i.e. in liberal arts colleges) which seems to have a double purpose. On the one hand the test provides an initial indication of an applicant's potential ability to be able to take a basic course in interpreting, i. e., a sort of diagnostic or admission test. The test is also used in training environments for diagnostic purposes (see Unde \& Wadensjö 2012; Wadensjö 2014). It tests language proficiency through an interpreting situation which would be an interpreted roleplay between the two working languages of the relevant interpreter. However, the construction of the test makes it very difficult to tease apart the different elements/components of what is tested. Do errors and difficulties depend upon poor language proficiency, poor interpreting technique, insufficient terminological knowledge within the domain of the interpreted situation, or something else? (Further to this test, see Unde \& Wadensjö 2012 on the difficulty of using role-play for diagnostic and examination purposes in dialogue interpreting. See further Wadensjö 2014.).

There are also instances of certification or diploma tests, which test language proficiency or interpreting or both. In Australia (NAATI ${ }^{3}$, National Accreditation Authority for Translators and Interpreters) and the UK (DPSI ${ }^{4}$, Diploma in Public Service Interpreting), interpreters are tested on interpreting tasks only. There are no language proficiency tests. The Swedish Kammarkollegiet (www.kammarkollegiet.se) authorizes Swedish interpreters. Their tests are taken in two steps, the first one consisting of an eliminatory written examination in which three tests are included, two of which test language proficiency5. The second step is a test of interpreting with scripted role plays.

This overview shows that language proficiency in interpreting seems to be assumed rather than systematically tested. In our project we hypothesize that interpreting into a weaker language is cognitively more demanding, which may affect the interpreting process. For conference interpreting, the effects on interpreting into stronger vs. weaker languages is well covered in directionality studies (see Chmiel 2016; Chang, C-Y 2009; Chang, C. \& Schallert 2007; Godijns \& Hinderdael 2005). To the best of our knowledge, this has so far not been covered in process-oriented research of dialogue interpreting.

For our project, the lack of generally accepted tests and levels for determining the language proficiency of dialogue interpreters is problematic for research on the impact of language asymmetry. Heterogeneity in the potential participants presents the risk of creating confounding variables. We therefore needed a method to test participants' language proficiency.

\subsection{Testing and self-assessing $\mathrm{L} 1$ and $\mathrm{L} 2$}

There are several ways to determine language proficiency in L1 and L2. Research within language testing in general has shown a complex relation between self-assessment and test scores. The correlation between various types of self-assessment and scores from testing is the topic of several studies, although, to our knowledge, not in interpreting studies. Many of them are somewhat based upon the descriptors of the CEFR. Runnels (2016) refers to a review study by Edele et al. (2015) in which more than 30 correlational studies were reviewed with mixed results. Edele et al. conclude (according to Runnels, p. 112) that this may be due to the quality of the instruments used, both for self-assessment and for the actual measurement of proficiency. Durán Escribano and Pierce McMahon (2010) studied the correlation between self-assessment and the test score in listening comprehension in the Dialang test (i.e., the language test taken by our participants, see further below). When self-assessing, their participants tended to overestimate their listening comprehension ability. One reason for this may be the fact that the participants were engineering students and L2 speakers of English. Although they were given some instructions on how to self-assess, they may

\footnotetext{
3 https://www.naati.com.au/

4 https://www.ciol.org.uk/dpsi

5 Swedish language proficiency is tested through a cloze test. Proficiency in the other language is tested through word translation (20 in context and 40 PSI-relevant terminology) from Swedish into the other working language.
} 
have been less aware of their linguistic capabilities in a foreign language than interpreting students or professional interpreters. Van Onna and Jansen (2006) also studied the correlation between selfassessment scores and Dialang test scores. The participants were professionals in 10 Dutch organizations who were being tested in their native language (Dutch), and another language (English, French or German). The participants tended to overestimate their own proficiency. Runnels $(2010,121)$ found no reliable correlation between Japanese language students' language proficiency in English, as measured by the TOEIC ${ }^{6}$ test, and their self-assessment scores, in terms of the CEFR descriptors, adapted for Japanese conditions. This lack of reliability was stronger for reading comprehension than for listening comprehension.

\subsection{Working definition and establishing criteria for test specifications}

Our working definition of asymmetrical language proficiency of the dialogue interpreter is phrased in terms of stronger and weaker working languages. The definition is individual-specific and situationbased. The stronger working language of a dialogue interpreter in a given interpreting situation is that working language which he/she states as the strongest in self-assessment and/or receives a higher score in a language proficiency test. Accordingly, the weaker working language of a dialogue interpreter in a given interpreting situation is that working language which he/she states as less strong in self-assessment and/or receives a lower score in a language proficiency test. This definition does not consider how the participants acquired their stronger and weaker language. ${ }^{7}$ Clearly, this working definition assumes the working hypothesis that interpreters actually do differ in proficiency when it comes to their two working languages. To operationalize this definition, we need a method or test, for determining the level of the participants' language proficiencies.

Our reasoning in finding a suitable test was that we wanted to test their language proficiency in the two interpreting languages, in a way that is task-relevant, but still independent of the particular task of interpreting. Hence, we aim to score their language proficiency and subsequently correlate it with their interpreting performance.

The test would need to answer to the following criteria:

1. Available for a wide range of languages, in order to accommodate our present and future needs (obligatory requirement)

2. Capable of testing (giving valid results) both native and non-native speakers of the tested language (obligatory requirement)

3. Testing proficiency components that we deemed relevant for application in an interpreting situation (obligatory)

4. Easy to administer, via computer/internet (preferable)

5. Giving immediate answer (preferable)

The Dialang test seemed to meet at least the obligatory requirements. It is a test developed under the auspices of the Council of Europe and, as indicated by its name, diagnoses the individual's language level (Dialang. Summary, n. d.). As per the Council of Europe's framework for language proficiency (CEFR) (Huhta et al. 2002), Dialang is available free of charge online ${ }^{8}$, and can be taken by anyone. It tests listening, writing, and reading. One drawback is that it does not test oral production, something that is obviously highly relevant for interpreting. The test is available in Swedish, French and Spanish (plus several other European languages, in total 14). The test matched our first criterion. However, when we recruited a doctoral student who was fluent in Polish, and as a consequence Polish was added to the material, we found that the test was not available in Polish. The Polish participants took the test for Swedish only. Their data is not included in this paper.

\footnotetext{
${ }^{6} \mathrm{https}: / /$ www.ets.org/toeic

7 Language acquisition questions were included in the demographic questionnaire but will not be reported here.

8 https://dialangweb.lancaster.ac.uk/
} 
In conclusion, in our data, we have two different methods for determining the participants' linguistic background: 1 . A sociolinguistic questionnaire on their language background and use as well as their own views on the strengths of their working languages; 2 . The Dialang test.

\section{Participants and testing}

Participants can be divided in two categories, namely last term students in public service interpreting at the Institute for Interpreting and Translation Studies at Stockholm University, and experienced interpreters who are Swedish state authorized interpreters with at least four years of at least part-time professional experience. All participants in this study have Swedish as one of their working languages (see Table 1). The other working languages are French, Spanish and Polish. The reasons for choosing these participants were their accessibility and also the fact that we have mastery of these languages in our research group, which strengthens the analysis.

\section{INSERT TABLE 1 ABOUT HERE}

\begin{tabular}{lcllllll}
\multirow{2}{*}{ Table 1. Participants } & \multicolumn{2}{c}{ Experienced } & \multicolumn{5}{c}{ Inexperienced } \\
\cline { 3 - 7 } Language & $\boldsymbol{N}$ & $\begin{array}{l}\text { Mean } \\
\text { age }\end{array}$ & $\begin{array}{l}\text { Mean } \\
\text { years of } \\
\text { experience }\end{array}$ & Gender & $\boldsymbol{N}$ & $\begin{array}{l}\text { Mean } \\
\text { age }\end{array}$ & Gender \\
\hline French & 3 & 52 & 8 & F & 2 & 27 & F \\
Polish & 2 & 49 & 8 & F & 2 & 27 & F \\
Spanish & 2 & 51 & 23 & $2 \mathrm{M} \mathrm{1F}$ & 2 & 48 & $\mathrm{~F}$ \\
\hline
\end{tabular}

In the self-screening background questionnaire, participants answered the following questions:

- Which language(s) do you consider your first language/mother tongue?

- Which language(s) do you consider your strongest?

- How much do you estimate that you use your different languages during your free time (please estimate in in \%, it should add up to $100 \%$ )?

- How much do you estimate that you use your different languages for work and/or education (please estimate in in \%, it should add up to $100 \%)$ ?

Due to space limitations, in this paper we will only discuss answers to the two first questions ${ }^{9}$.

The full Dialang test takes about 2 hours, which was deemed to be too time-consuming in view of the other tests that the participants were asked to go through (see above). They were therefore given only three parts of the test, namely the placement test, which tests vocabulary, the listening proficiency test, and the writing proficiency test. In total the three parts take about 40 minutes to an hour to complete (See Appendix 1 for descriptors of the different levels of these proficiencies in Dialang). The placement test was voluntary. One participant chose not to take it.

\section{Results: language proficiency assessment on an individual level}

Participants took the placement test first. The results of the placement tests are presented as a numerical score, with the maximum being 1000 (Huhta 2007). For listening and written proficiency, the test scores are given as CEFR-levels (A1 etc) (Alderson 2005, 105).

\footnotetext{
${ }^{9}$ Participants were also asked which languages they interpreted to and from, and whether they did interpret to and from their two working languages and (except for two cases) not any other languages.
} 
Tables 2 and 3 show the results from the Dialang test with the French and Spanish ${ }^{10}$ participants.

\section{INSERT TABLE 2 ABOUT HERE}

Table 2. Participants'Swedish language proficiency: Dialang self-assessment and Dialang test-scores

\begin{tabular}{lllll} 
& & \multicolumn{3}{c}{ Swedish (Dialang) } \\
\cline { 3 - 5 } Participant & & $\begin{array}{l}\text { Vocabulary } \\
\text { scores }\end{array}$ & Listening & Writing \\
\hline & French & & C1 & B2 \\
\hline 1 & Student & 980 & C2 & B2 \\
3 & Student & 880 & C2 & C1 \\
4 & Student & 1000 & C2 & C2 \\
5 & Professional & 1000 & C1 & C2 \\
6 & Professional & 980 & C2 & C1 \\
\hline & Professional & 900 & & \\
\hline 7 & Spanish & & C2 & C1 \\
8 & Student & 1000 & C2 & B1 \\
\hline 9 & Student & n/a & B2 & C2 \\
\hline 10 & Professional & 882 & C2 & C2 \\
\hline
\end{tabular}

As can be seen from Table 2, in the numerical scores of the Dialang vocabulary test of Swedish results range from 880 to 1000, with a mean value of 970 , i.e. a very high proficiency. Also, the participants' proficiency is quite high given their test scores for both listening comprehension and writing skills in Swedish, although with some variation especially for written proficiency.

Table 3 shows the Dialang results for the other language, for the French and Spanish participants.

\section{INSERT TABLE 3 ABOUT HERE}

Table 3. Participants' other language proficiencies: Dialang

other language (Dialang)

\begin{tabular}{lllll}
\hline Participant & & $\begin{array}{l}\text { Vocabulary } \\
\text { scores }\end{array}$ & Listening & Writing \\
\hline & French & & & \\
\hline 1 & Student & 580 & C1 & B1 \\
2 & Student & 806 & B2 & B2 \\
3 & Student & 435 & B2 & B1 \\
4 & Professional & 1000 & C1 & C2
\end{tabular}

10 Polish participants not included, see Section 2.5. 


\begin{tabular}{lllll}
5 & Professional & 980 & B1 & C2 \\
6 & Professional & 900 & B2 & B2 \\
\hline 7 & Spanish & & & \\
\hline 8 & Student & 761 & B2 & C2 \\
9 & Student & n/a & B1 & C1 \\
10 & Professional & 821 & A2 & C1 \\
11 & Professional & 923 & B2 & C1 \\
\hline
\end{tabular}

Table 3 shows a much more heterogeneous picture at group level for proficiency levels in the other language. This is reflected both in the vocabulary test, which ranges from a rather low 435 up to 1000. The other test scores range from a rather low of A2 up to the highest level C2. At an individual level also, there is more variation than in the results for Swedish proficiency.

The data show that at group level, we can assume that Swedish is the stronger language. The figures also show that participants seem to have asymmetrical language proficiency.

The data in Tables 2 and 3 indicate the strongest language for each participant based on the Dialang results. We present the data in Table 4 and compare them with the self-reported strongest language from the demographic questionnaire.

\section{INSERT TABLE 4 ABOUT HERE}

Table 4. Comparison of participants'strongest language based on Dialang results and self-reports.

\begin{tabular}{lllll}
\multicolumn{5}{c}{ Strongest language } \\
\hline Participant & & Dialang & Self-report & Difference \\
& & & & \\
\hline 1 & French & & SE & Same \\
2 & Student & SE & FR/SE & Discrepancy \\
3 & Student & SE & SE & Same \\
4 & Student & SE & SE & Discrepancy \\
5 & Professional & SE/FR & SE & Discrepancy \\
6 & Professional & SE/FR & SE & Discrepancy \\
\hline & Professional & SE/FR & & \\
\hline 7 & Spanish & & SE & Same \\
8 & Student & SE & SE & Same \\
9 & Student & SE? & ES & Discrepancy \\
10 & Professional & SE & SE/ES & Same \\
11 & Professional & SE/ES & SE & Discrepancy \\
\hline & Professional & SE/ES & & \\
\cline { 2 - 5 } & & & & \\
\hline
\end{tabular}


When comparing the results from Dialang at an individual level and the self-reported strongest language we find that half of the participants show a discrepancy between the language the language they self-report as strongest and the Dialang result.

On average, the test scores of the participants in this study indicate high language proficiency levels in both their working languages. This is probably due to the recruitment procedure and requirements. The professionals were all state authorized public service interpreters. They have passed several tests, both written and oral, both for terminology relevant to public service interpreting, in both languages, as well as tests in actual interpreting in various settings. It is generally acknowledged that these tests are quite difficult to pass and require previous experience as an interpreter. Previous training is also preferred. The student participants had less experience in interpreting, but their language proficiency in both working languages had been tested via an admission test upon applying to the university course in public service interpreting.

\section{Discussion and final remarks}

The research question of this contribution was to explore how the proficiency in the working languages of a given dialogue interpreter can be defined and determined (by what method and measure?) for further study. In approximately half of the cases, the scores from the Dialang test were not supported by the self-reported strongest language provided in our demographic questionnaire.

There are a few possible reasons for such discrepancies. Firstly, assuming that the Dialang results are valid, vocabulary, writing and listening proficiencies were tested, whereas the question in the questionnaire asked for a holistic self-report on strongest language. Secondly, the language history and environment of the participants is highly diverse and may therefore be difficult to capture adequately both in questionnaires and in testing instruments. We would argue for the importance of using more than one method like triangulation.

The test scores and the answers to the questionnaire (some of which were not reported in this paper) are valuable for our project since they give us deeper knowledge of the background and language proficiency of our participants. The cases that showed a discrepancy as presented in Tables 2-4 are particularly noteworthy. They contribute to a more fine-grained analysis of our data, especially the scripted roleplays.

Dialang was chosen as it is a validated test with easy access and scoring. There were disadvantages also. The first one is that once a participant has finished the test, Dialang presents the result as a score only, with no access to the individual answers. Although Dialang exists in many languages, these are mainly European languages and the test does not cover some common public service interpreting languages, including Farsi or Arabic ${ }^{11}$. The pros still outweigh the cons, however.

The validity of language tests and correlations between different scores such as test scores and selfassessment is usually based on data from cohorts larger than those in this study. Larger groups of participants make it possible to draw conclusions at a group level. Language proficiency testing of dialogue interpreters was not a particularly prominent feature of our project (The Invisible Process), at least initially. The vital importance of coming up with a definition of asymmetrical language proficiency and studying its impact on the interpreting process, however, necessitated further exploration thereof. A more general conclusion is that this is an area in need of further theoretical as well as applied research.

\footnotetext{
11 Dialang is currently being updated in the Dialang 2.0 project http://wp.lancs.ac.uk/ltrg/projects/dialang-2-0/
} 


\section{Acknowledgements}

This article is part of the Swedish Research Council-funded project Invisible process - cognition and working memory of dialogue interpreting (VR 2016-01118). We are very grateful for this funding opportunity. We would also like to thank reviewers and editors for their fruitful comments.

\section{References}

AIIC. Working languages. aiic.net. April 29, 2012. Accessed November 10, 2018. http://aiic.net/p/4004

Angelelli, Claudia V. 2007. “Assessing Medical Interpreters.” The Translator 13 (1): 63-82.

Angelelli, Claudia, and Christian Degueldre. 2002. "Bridging the Gap between Language for General Purposes and Language for Work: An Intensive Superior-level Language/ skill Course for Teachers, Translators, and Interpreters." In Developing Professional-level Language Proficiency, edited by Betty L. Leaver, and Boris Shekhtman, 77-96. Cambridge: Cambridge University Press.

Bartłomiejczyk, Magdalena. 2006. "Strategies of simultaneous interpreting and directionality." Interpreting 8 (2): 149-174.

Blasco Mayor, María Jesús. 2015. "L2 proficiency as predictor of aptitude for interpreting. An empirical study." Translation and Interpreting Studies 10 (1): 108-132.

Bot, Kees de. 2000. "Simultaneous interpreting as language production." In Language processing and simultaneous interpreting: interdisciplinary perspectives, edited by Birgitta Englund Dimitrova and Kenneth Hyltenstam, 65-88. Amsterdam/Philadelphia: John Benjamins Publishing.

Bot, Kees de. 1992. "Self-Assessment of Minority Language Proficiency." In The Construct of Language Proficiency: Applications of Psychological Models to Language Assessment, edited by Ludo Verhoeven and John H.A.L. de Jong, 137-146. Amsterdam/Philadelphia: John Benjamins.

Cai, Rendong, Yanping Dong, Nan Zhao, and Jiexuan Lin. 2015. "Factors contributing to individual differences in the development of consecutive interpreting competence for beginner student interpreters" The Interpreter and Translator Trainer 9 (1): 104-120.

Chang, Chia. \& Schallert, Diane. L. 2007. "The impact of directionality on Chinese/English simultaneous interpreting." Interpreting 9 (2): 137-176.

Chang, Chieh-Ying. 2009. Testing Applicability of Eye-tracking and fMRI to Translation and Interpreting Studies: An Investigation into Directionality. Doctoral thesis. University of London.

Christoffels, Ingrid K., Annette M.B de Groot, and Judith F. Kroll. 2006. Memory and language skills in simultaneous interpreters: The role of expertise and language proficiency. Journal of Memory and Language 54: 324-345

Chmiel, Agnieszka. 2016. "Directionality and Context Effects in Word Translation Tasks Performed by Conference Interpreters." Poznań Studies in Contemporary Linguistics 52 (2): 269-295.

Conseil Européen pour les langues. European Language Council. n.d. DIALANG. Accessed November 2, 2018. http://www.celelc.org/projects/Past_Projects/DIALANG/index.html

Council of Europe. Conseil de l'Europe. n.d. Common European Framework of Reference for Languages: Learning, teaching, assessment. Accessed November 2, 2018. 
https://www.coe.int/en/web/portfolio/the-common-european-framework-of-reference-forlanguages-learning-teaching-assessment-cefr-

DIALANG - A Diagnostic Language Assessment System for Adult Learners. In: Council of Europe, Common European Framework of Reference for Languages: Learning, Teaching, Assessment. Case Studies, 130-144. Strasbourg: Council of Europe Publishing.

Dialang. Summary. n.d. Accessed Oct 30, 2018. https://www.llas.ac.uk/resources/mb/1676.html,

Dillinger, Michael. 1994. "Comprehension during interpreting: What do interpreters know that bilinguals don't." In Bridging the Gap: Empirical research in simultaneous interpretation, edited by Sylvie Lambert and Barbara Moser-Mercer, 155-189. Amsterdam/Philadelphia: John Benjamins.

Dose, Stefanie. 2014. "Putting directionality into context." Stellenbosch Papers in Linguistics Plus 45 (1): 71-88.

Durán Escribano, Pilar and Pierce McMahon, Joana. 2010. "Self-assessment Based on Language Learning Outcomes: A Study with First Year Engineering Students." Revista Alicantina de Estudios Ingleses 23: 133-148.

Edele, Aileen, Julian Seuring, Cornelia Kristen, and Petra Stanat. 2015. "Why bother with testing? The validity of immigrants' self-assessed language proficiency." Social Science Research 52: 99-123.

Godijns, Rita, and Michael Hinderdael. 2005. Directionality in interpreting: The 'retour' or the native? Gent: Communication and Cognition.

Huhta, Ari, Sari Luoma, Mats Oscarson, Kari Sajavaara, and Alex Teasdale. 2002. "DIALANG, A Diagnostic Language Assessment System for Adult Learners." Common European Framework of Reference for Languages: Learning, Teaching, Assessment: Case Studies, 130-144. Gothenburg: Department of Education, Language and Literature Unit.

Huhta, Ari. 2007. "The Vocabulary Size Placement Test in DIALANG: why do users love and hate it?" In A Human Touch to Language Testing, edited by Cecilie Carlsen and Eli Moe, 44-57. Oslo: Novus Press,

Hulstijn, Jan H. 2015. Language Proficiency in Native and Non-native Speakers: Theory and research. Amsterdam/Philadelphia: John Benjamins.

Jiménez Ivars, Amparo, Daniel Pinazo Catalayud \& Marta Ruiz i Forés. 2014. "Self-efficacy and language proficiency in interpreter trainees." The Interpreter and Translator Trainer 8 (2): 167-182.

Moser-Mercer, Barbara. 1994. "Aptitude Testing for Conference Interpreting: Why, When and How." In Bridging the Gap: Empirical research in simultaneous interpretation, edited by Sylvie Lambert and Barbara Moser-Mercer, 57-68. Amsterdam/Philadelphia: John Benjamins.

Onna, Bert van and Carel Jansen. 2006. "How multilingual are the Dutch really? On proficiency in Dutch, English, French, and German in Dutch organizations." Belgian Journal of English Language and Literatures New Series 4 (4): 169-180.

Pavlović, Nataša, and Kristian T. H. Jensen. 2009. "Eye tracking translation directionality.” In Translation research projects 2 edited by Anthony Pym and Alexander Perekrestenko, 93-109. Tarragona: Universitat Rovira i Virgil.

Romaine, Suzanne. 1995. Bilingualism. Oxford/Massachusets: Blackwell. 
Rosiers, Alexandra, June Eyckmans, and Daniel Bauwens. 2011. "A story of attitudes and aptitudes?: Investigating individual difference variables within the context of interpreting." Interpreting 13 (1): 53-69.

Runnels, Judith. 2010. "Self-assessment accuracy: Correlations between Japanese English learners' self-assessment to the CEFR-Japan's can do statements and scores on the TOEIC." Taiwan Journal of TESOL 13 (1): 105-137.

Thomsen, Thomas. 2018. Tolkningsstrategier i ljuset av språkkompetens, tolkningsriktning och tolkerfarenhet. [Interpreting strategies in the light of language competence, directionality and interpreting experience] Master's thesis. Stockholms universitet: Institutionen för svenska och flerspråkighet. http://su.diva-portal.org/smash/get/diva2:1217466/FULLTEXT02.pdf Accessed November 10, 2018.

Tiselius, Elisabet and Kayel, Sneed. (submitted). "Gaze and eye-movements in dialogue interpreting: An eye-tracking study."

Tospråkstesten. 2016. Pilotprojekt. Evalueringsrapport. (2016). Oslo: Integrerings- og mangfoldsdirektoratet.

https://www.tolkeportalen.no/Global/tolking/EvalueringsrapportTospraktesten2016.pdf Accessed November 8, 2018.

Tzou, Yeh-Zu, Zohreh R Eslami, Hsin-Chin Chen, and Vaid Jyotsna. 2011. "Effect of language proficiency and degree of formal training in simultaneous interpreting on working memory and interpreting performance: Evidence from Mandarin-English speakers". International Journal of Bilingualism 16 (2): 213-227.

Unde, Bengt and Cecilia Wadensjö, eds. 2012. “Om bedömning av tolkning inom grundutbildningen till kontakttolk". [On the assessment of interpreting within the basic contact interpreter education] In HiOA Rapport 12 Hanne Skaaden and Tatiana R Felberg, eds, 113-124. Oslo: Høgskolen i Oslo og Akershus.

Wadensjö, Cecilia. 2014. "Perspectives on role play: analysis, training and assessments." The Interpreter and Translator Trainer 8 (3): 437-451. 

test takers. (Based on CEFR.)

\section{CEF Level LISTENING}

A1 Your test result suggests that you are at or below level A1 in listening on the Council of Europe scale. At this level, people can understand very simple phrases about themselves, people they know and things around them, when people speak slowly and clearly.

A2 Your test result suggests that you are at level A2 in listening on the Council of Europe scale. At this level, people can understand expressions and the most common words about things which are important to them, e.g. very basic personal and family information, shopping, their jobs. They can get the main point in short, clear, simple messages and announcements.

B1 Your test result suggests that you are at level B1 in listening on the Council of Europe scale. At this level, people can understand the main points of clear 'standard' speech on familiar matters connected with work, school, leisure etc. In TV and radio current affairs programmes or programmes of personal or professional interest, they can understand the main points provided the speech is relatively slow and clear. B2 Your test result suggests that you are at level B2 in listening on the Council of Europe scale. At this level, people can understand longer stretches of speech and lectures and follow complex lines of argument provided the topic is reasonably familiar. They can understand most TV news and current affairs programmes.

C1 Your test result suggests that you are at level C1 in listening on the Council of Europe scale. At this level, people can understand spoken language even when it is not clearly structured and when ideas and thoughts are not expressed in an explicit way. They can understand television programmes and films without too much effort. C2 Your test result suggests that you are at level C2 in listening on the Council of Europe scale. At this level, people can understand any kind of spoken language, both when they hear it live and in the media. They also understand a native speaker who speaks fast if they have some time to get used to the accent.

\section{CEF Level WRITING}

A1 Your test result suggests that you are at level A1 in writing on the Council of Europe scale. At this level, people can write a short simple postcard, for example sending holiday greetings. They can fill in forms with personal details, for example writing their name, nationality and address on a hotel registration form.

A2 Your test result suggests that you are at level A2 in writing on the Council of Europe scale. At this level people can write short, simple notes and messages about everyday matters and everyday needs. They can write a very simple personal letter, for example thanking someone for something.

B1 Your test result suggests that you are at level B1 in writing on the Council of Europe scale. At this level people can write simple texts on topics which are familiar or of personal interest. They can write personal letters describing experiences and impressions.

B2 Your test result suggests that you are at level B2 in writing on the Council of Europe scale. At this level people can write clear detailed texts on a wide range of subjects related to their interests. They can write an essay or report, passing on information and presenting some arguments for or against a point of view. They can write letters highlighting the personal significance of events and experiences. C1 Your test result suggests that you are at level C1 in writing on the Council of Europe scale. At this level, people can write clear and well-structured text and express their points of view at some length. They can write about complex subjects in a letter, an essay or a report, underlining what they think are the most important points. They can write different kinds of texts in an assured and personal style which is appropriate to the reader in mind.

C2 Your test result suggests that you are at level C2 in writing on the Council of Europe scale. At this level, people can write clearly and smoothly and in an appropriate style. They can write complex letters, reports or articles in such a way that helps the reader to notice and remember important points. They can write summaries and reviews of professional or literary texts.

(Council of Europe. Conseil de l'Europe. n.d., pp. 237-238) 


\section{Bionotes}

Birgitta Englund Dimitrova has a PhD in Slavic Linguistics and is Professor Emerita of Translation Studies at Stockholm University, Sweden. Her research interests are mainly within Slavic linguistics, cognition, bilingualism and translation/interpreting. Her publications include monographs (Expertise and Explicitation in the Translation Process, Benjamins, 2005), several edited volumes and special issuses and a large number of papers. For more information on current research, see https://www.su.se/english/profiles/benglund-1.183201

Elisabet Tiselius has a PhD in Interpreting Studies, is Senior Lecturer at Stockholm University and Swedish state authorized public service interpreter, EU accredited and AIIC member. Tiselius. She is affiliated to the research group on Childhood Cancer Health Care at Karolinska Institutet and the research group on Interpreter and Interpreter training at the Western Norway University of Applied Sciences Together with Englund Dimitrova she received Swedish Research Council grant to investigate cognitive aspects of dialogue interpreting (VR grant 2016-01118). Tweets @tulkur 